\title{
Hemodynamic Effects of Heat-Killed Group B $\beta$-Hemolytic Streptococcus in Newborn Lambs: Role of Leukotriene $\mathrm{D}_{4}{ }^{1}$
}

\author{
MICHAEL D. SCHREIBER, ROBERT F. COVERT, AND LORNA J. TORGERSON \\ Department of Pediatrics, University of Chicago, and Michael Reese Hospital and Medical Center, \\ Chicago, Illinois 60637
}

\begin{abstract}
Group B $\beta$-hemolytic streptococcus (GBS) infection is an important cause of neonatal pneumonia and sepsis. GBS infection is frequently associated with persistent pulmonary hypertension of the newborn. To better understand the early pulmonary hypertension phase of GBS-induced acute lung injury in a conscious animal, we characterized the pulmonary and systemic hemodynamic response of spontaneously breathing, chronically instrumented newborn lambs to injections of heat-killed type Ib GBS, 0.1-9.0 $\times 10^{9}$ colony forming units. Heat-killed GBS caused marked dose-dependent increases in mean pulmonary arterial pressure and calculated pulmonary vascular resistance, 190 and $370 \%$ at the maximum dose, respectively. Similarly, GBS caused dose-dependent increases in mean systemic arterial pressure and systemic vascular resistance $(28.5$ and $108 \%$ at the maximum dose, respectively) and a decrease in cardiac output (33.5\%). Arterial oxygen tension worsened at the higher doses. GBS-induced pulmonary hypertension was decreased by two structurally unrelated, putative leukotriene $\mathrm{D}_{4}$ receptor antagonists. Pretreatment with LY171883 blocked GBS-induced pulmonary hypertension by $95 \%$, and WY48,252 attenuated this effect by $27 \%$. Both drugs completely blocked the hemodynamic effects of exogenous leukotriene $D_{4}$. For comparison, several lambs received bolus injections of live GBS, either alone or after pretreatment with LY171883. The hemodynamic response to live GBS and attenuation of that response by LY171883 were similar to those caused by similar doses of heat-killed GBS. Thus, bolus injections of heat-killed GBS provide a reproducible model of pulmonary hypertension in conscious newborn lambs. In addition, the sulfidopeptide leukotrienes appear to be important mediators of GBS-induced pulmonary hypertension in newborn lambs. (Pediatr Res 31: 121-126, 1992)
\end{abstract}

\section{Abbreviations}

GBS, group B $\beta$-hemolytic streptococcus

LT, leukotriene

TX, thromboxane

cfu, colony forming units

PVR, pulmonary vascular resistance

SVR, systemic vascular resistance

PAP, pulmonary arterial pressure

SAP, systemic arterial pressure

Received March 26, 1991; accepted August 26, 1991

Correspondence and reprint requests: Michael D. Schreiber, M.D., Department of Pediatrics, Box 325, University of Chicago, 5841 S. Maryland Ave. Chicago, IL 60637.

Supported by a grant from the American Lung Association.

${ }^{1}$ Presented in part at the Society for Pediatric Research meeting, Anaheim CA, May, 1990.
GBS infection is a major cause of neonatal pneumonia and sepsis. The overall mortality of GBS sepsis is reported to be as high as $50 \%$. GBS infection is frequently associated with persistent pulmonary hypertension of the newborn and is an important cause of neonatal mortality $(1,2)$. The clinical and experimental cardiopulmonary effects of GBS are very similar to those seen in gram-negative sepsis (3-10). Numerous reports have demonstrated the importance of the cyclooxygenase products of arachidonic acid metabolism, especially $\mathrm{TXA}_{2}$, in the pathogenesis of GBS-induced pulmonary hypertension (10-13). Limited information is available regarding the importance of the lipoxygenase products of arachidonic acid metabolism, specifically the vasoactive sulfidopeptide $\mathrm{LTC}_{4}$ and $\mathrm{D}_{4}$ in GBS-induced pulmonary hypertension $(4,8)$.

The purposes of the present study were to characterize the hemodynamic response of spontaneously breathing, chronically instrumented newborn lambs to injections of heat-killed GBS and to investigate the contribution of $\mathrm{LTD}_{4}$ to GBS-induced pulmonary hypertension. The latter was studied by pretreating lambs with one of two structurally unrelated, putative $\mathrm{LTD}_{4}$ receptor antagonists (Fig. 1): LY 171883 (Lilly Research Laboratory, Indianapolis, IN) or WY 48,252 (Wyeth-Ayerst Research, Princeton, NJ). In addition, studies were performed using live GBS to verify that the response to heat-killed GBS was not caused by the processing of the bacteria.

\section{MATERIALS AND METHODS}

Surgical Preparation. Twenty-four newborn lambs, less than a week of age, were instrumented under general anesthesia, which was induced by having the lambs breathe a mixture of oxygen and isoflurane. The lambs were intubated with a $4.5-\mathrm{mm}$ inner diameter endotracheal tube and mechanically ventilated with an animal ventilator. Anesthesia was maintained with $1-2 \%$ isoflurane. Polyvinyl catheters were placed under direct visualization into a hindlimb artery and vein and advanced into the descending aorta and inferior vena cava, respectively. A left lateral thoracotomy was performed in the fourth intercostal space, and the pericardium was incised. Polyvinyl catheters were then placed into the internal thoracic artery and vein and advanced into the ascending aorta and right atrium, respectively. Polyvinyl catheters were placed into the main pulmonary artery and left atrium. An appropriately sized (7.5- to $11.0-\mathrm{mm}$ internal diameter), in vitro calibrated electromagnetic flow transducer (Carolina Medical Electronics, Inc., King, NC) was placed around the main pulmonary artery trunk to measure cardiac output. The ductus arteriosus was ligated. A chest tube was placed into the pleural space to drain air and fluid postoperatively. The thoracotomy incision was closed in layers. The catheters were filled with heparin, plugged, and, along with the transducer cable, brought 
to the skin and secured to the lamb's flank. The lamb was then weaned from mechanical ventilation, and, after recovery from anesthesia, returned to its mother. At least $3 \mathrm{~d}$ were allowed for recovery before any studies were performed. Lambs received daily intramuscular injections of gentamicin sulfate.

This protocol was approved by the Institutional Animal Care and Use Committee.

Measurements and Analyses. Pulmonary and systemic arterial and right and left atrial pressures were measured using Statham $23 \mathrm{Db}$ pressure transducers. Mean pressures were obtained by electrical integration. Cardiac output was measured using an electromagnetic flowmeter (Carolina Medical Electronics, Inc.). All hemodynamic variables were continuously recorded on an eight-channel direct-writing recorder (Gould Electronics, Cleveland, $\mathrm{OH}$ ). Systemic arterial $\mathrm{pH}$ and blood gas tensions were measured using a Radiometer ABL 30 acid-base blood gas analyzer (Radiometer, Inc., Copenhagen, Denmark). PVR and SVR were calculated per kg using standard formulas.

The means and SD were calculated for the hemodynamic variables and systemic arterial $\mathrm{pH}$ and blood gas tensions during each of the experimental conditions and were compared using two-way analysis of variance and the Scheffe $t$ test for multiple comparisons, the Wilcoxon paired test, paired $t$ tests, or linear regression analysis, as appropriate. A $p$ value $<0.05$ was considered statistically significant (14).

Experimental Protocol. Heat-killed GBS dose-response studies. To determine the pulmonary and systemic hemodynamic effects of heat-killed GBS, six lambs received multiple doses $(0.1,0.25$, $0.5,1.0,3.0,6.0$, and $9.0 \times 10^{9} \mathrm{cfu}$ ) of GBS during a single study day. The maximal dose given varied in that $6-9 \times 10^{9} \mathrm{cfu}$ could not be given to every lamb because cardiac output fell so significantly that higher doses might have caused death.

Based on preliminary data, GBS injections were given at least $20 \mathrm{~min}$ apart to prevent tachyphylaxis. In addition to the above doses, lambs received several doses of $1 \times 10^{6}$ cfu GBS throughout the study day to determine whether the hemodynamic response to a single repeated dose of GBS changed after multiple injections.

$L T D_{4}$ and $L T$ receptor antagonism. To determine whether the

LY 171883<smiles>CCCc1c(OCCCCc2nnn[nH]2)ccc(C(C)=O)c1O</smiles>

W Y 48,252<smiles>O=S(=O)(Nc1cccc(OCc2ccc3ccccc3n2)c1)C(F)(F)F</smiles>

FPL 57231

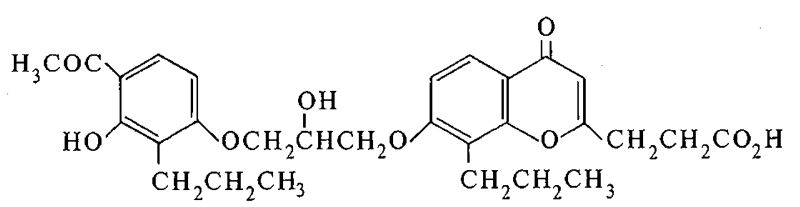

Fig. 1. The structures of LY 171883 (top) and WY 48,252 (middle). FPL57231 (bottom) is shown for comparison.
$\mathrm{LTD}_{4}$ receptor antagonists LY 171883 and WY 48,252 block the hemodynamic effects of exogenous $\mathrm{LTD}_{4}$, lambs were injected with $\mathrm{LTD}_{4}$ before and after treatment with one of these two drugs.

Baseline measurements were made, as above, while the lambs were breathing spontaneously and resting in a sling. Lambs then received an i.v. injection of $\mathrm{LTD}_{4}, 1 \mu \mathrm{g} / \mathrm{kg}$, which served as a control injection, and the effects were recorded. At least 30 min later, lambs received either LY171883 $(20 \mathrm{mg} / \mathrm{kg}, n=7$ lambs $)$ or WY $48,252\left(30 \mathrm{mg} / \mathrm{kg}, n=8\right.$ lambs). The dose of $\mathrm{LTD}_{4}$ was repeated, and the effects were again recorded.

$G B S$ and $L T$ receptor antagonism. Heat-killed GBS. To determine the contribution of LT to the hemodynamic changes caused by GBS injection, one of two putative $\mathrm{LTD}_{4}$ receptor antagonists; LY171883 or WY 48,252, was studied. Baseline measurements were made, as above, while the lambs were breathing spontaneously and resting in a sling. Lambs then received an i.v. injection of $1 \times 10^{9} \mathrm{cfu}$ of heat-killed GBS, which served as a control injection, and the effects were recorded. This GBS dose was chosen because it caused a reproducible $50-100 \%$ increase in mean pulmonary arterial pressure with minimal systemic hemodynamic effects. Thirty min later, lambs received either LY $171883(20 \mathrm{mg} / \mathrm{kg}, n=7$ lambs) or WY $48,252(30 \mathrm{mg} / \mathrm{kg}$, $n=8$ lambs). Before repeating the dose of $1 \times 10^{9} \mathrm{CFU}$ of heatkilled GBS, LT blockade was confirmed by injecting exogenous $\mathrm{LTD}_{4}(1 \mu \mathrm{g} / \mathrm{kg})$. The effects were again recorded.

Live GBS. To determine whether the hemodynamic response to heat-killed GBS was similar to the response to live bacteria, three lambs received an injection of live GBS before and after pretreatment with LY171883. The lambs received two injections of live GBS, one alone and the other after pretreatment with LY171883 $(20 \mathrm{mg} / \mathrm{kg})$. Injections were separated by at least 48 $\mathrm{h}$. While the lambs rested in a sling, baseline hemodynamic variables and arterial $\mathrm{pH}$ and blood gas tensions were measured. The hemodynamic variables were recorded before and after LY 171883 or saline control and before and after live GBS $(1 \times$ $10^{9} \mathrm{cfu}$ ) was injected. Arterial $\mathrm{pH}$ and blood gas tension measurements were repeated 5 and 20 min after live GBS injection. Lambs received parenteral antibiotics after each day's study and were clinically well before receiving a second injection of live GBS.

Left atrial injection of $G B S$. To determine whether the effect of GBS on the pulmonary circulation was greater than that on the systemic circulation because of a "first-pass" phenomenon by which GBS may have its greatest effect at the first capillary bed encountered, we compared GBS injections into the inferior vena cava with injections into the left atrium.

On a separate study day, three lambs received injections of heat-killed GBS $\left(1 \times 10^{9} \mathrm{cfu}\right)$ : two into the inferior vena cava, and two into the left atrium. Hemodynamic measurements were made before and after injections of GBS and at least $20 \mathrm{~min}$ were allowed between injections. The order of injections was randomly assigned.

GBS and Drug Preparations. GBS, type Ib, was isolated from the blood of a newborn infant who developed early-onset sepsis at the University of Chicago Intensive Care Nursery. Bacteria were grown in Todd-Hewitt broth for $18-36 \mathrm{~h}$ at $37^{\circ} \mathrm{C}$ to late log phase and harvested by centrifugation at $5000 \mathrm{rpm}$ for $15 \mathrm{~min}$. Bacteria were resuspended in sterile normal saline to a concentration determined by serial viable counts to be $1 \times 10^{9} \mathrm{cfu} / \mathrm{mL}$. Live bacteria were used on the day of harvesting. Heat-killed bacteria were obtained by heating bacteria to $60^{\circ} \mathrm{C}$ for $60 \mathrm{~min}$. GBS killing was confirmed by no growth on blood agar. Aliquots of heat-killed GBS were stored at $-70^{\circ} \mathrm{C}$ until the study day.

LY171883, 1-[2-hydroxy-3-propyl-4-[4-(1H-tetrazol-5-yl)butoxy]phenyl] ethanone, was dissolved in $10 \mathrm{~mL}$ of normal saline, prepared fresh each study day, and infused i.v. over $10 \mathrm{~min}$. WY 48,252, 1,1,1-trifluoro-N[3-(2-quinolinylmethoxy)phenyl] methanesulfonamide, was given i.v. to three lambs and enterally to five lambs. The i.v. solution was prepared by dissolving WY 
48,252 , in $1-3 \mathrm{~mL}$ of $90 \%$ ethanol. The WY 48,252 ethanol mixture was then dissolved in $9 \mathrm{~mL}$ of $0.9 \%$ normal saline and given over $10 \mathrm{~min}$. The enteral preparation was prepared in 2 $\mathrm{mL}$ of $90 \%$ ethanol and given by orogastric tube. GBS was injected $20 \mathrm{~min}$ after the i.v. infusion and $1 \mathrm{~h}$ after the enteral infusion.

$\mathrm{LTD}_{4}$ was stored under argon at $-70^{\circ} \mathrm{C}$ until use. $\mathrm{LTD}_{4}(1 \mu \mathrm{g} /$ $\mathrm{kg}$ ) was diluted in normal saline to a volume of $1.0 \mathrm{~mL}$ and i.v. injected over $10 \mathrm{~s}$.

\section{RESULTS}

Heat-Killed GBS Dose-Response Studies. Intravenous injections of heat-killed GBS increased mean PAP and calculated PVR in a dose-dependent manner $(p<0.0001)$ (Fig. 2). The maximum response occurred $30-90 \mathrm{~s}$ after injection. The mean maximum dose, normalized for weight $\left[1.26(0.70 \mathrm{SD}) \times 10^{9}\right.$ $\mathrm{cfu} / \mathrm{kg}$ ], increased mean PAP $190 \%$ from 18.3 (3.9 SD) to a maximum of $53.0(8.7 \mathrm{SD}) \mathrm{mm} \mathrm{Hg}(p<0.001)$. At this dose, PVR similarly increased $370 \%$ from $0.079(0.027 \mathrm{SD})$ to 0.371 $(0.205 \mathrm{SD}) \mathrm{mm} \mathrm{Hg} \cdot \mathrm{mL}^{-1} \cdot \mathrm{min} \cdot \mathrm{kg}(p<0.01)$. PAP and PVR returned to baseline within 5-15 min taking longer for the higher doses.

Mean SAP and calculated SVR also increased in a dosedependent manner $(p<0.005$, Fig. 3 ). The maximum response occurred over a similar time period. The mean maximum dose given increased SAP $28.5 \%$ from 73.3 (9.3 SD) to 94.2 (17.7 SD) $\mathrm{mm} \mathrm{Hg}(p<0.005)$. Calculated SVR increased $108 \%$ from 0.311 $(0.100 \mathrm{SD})$ to $0.674(0.440 \mathrm{SD}) \mathrm{mm} \mathrm{Hg} \cdot \mathrm{mL}^{-1} \cdot \mathrm{min} \cdot \mathrm{kg}(p<$ $0.05)$. SAP and SVR returned to baseline within 5-15 min.

Cardiac output $/ \mathrm{kg}$ decreased in a dose-dependent manner $(p$ $<0.005$ ) (Fig. 3). The mean maximum dose given decreased cardiac output $33.5 \%$ from 254 (66 SD) to $169(72 \mathrm{SD}) \mathrm{mL}$. $\mathrm{min}^{-1} \cdot \mathrm{kg}^{-1}$. Atrial pressures increased slightly at the higher doses. Mean left atrial pressure increased from 0 to $4 \mathrm{~mm} \mathrm{Hg}(p<$ 0.04 ) and mean right atrial pressure increased from -1 to $5 \mathrm{~mm}$ $\mathrm{Hg}(p<0.02)$. Heat-killed GBS caused no significant change in
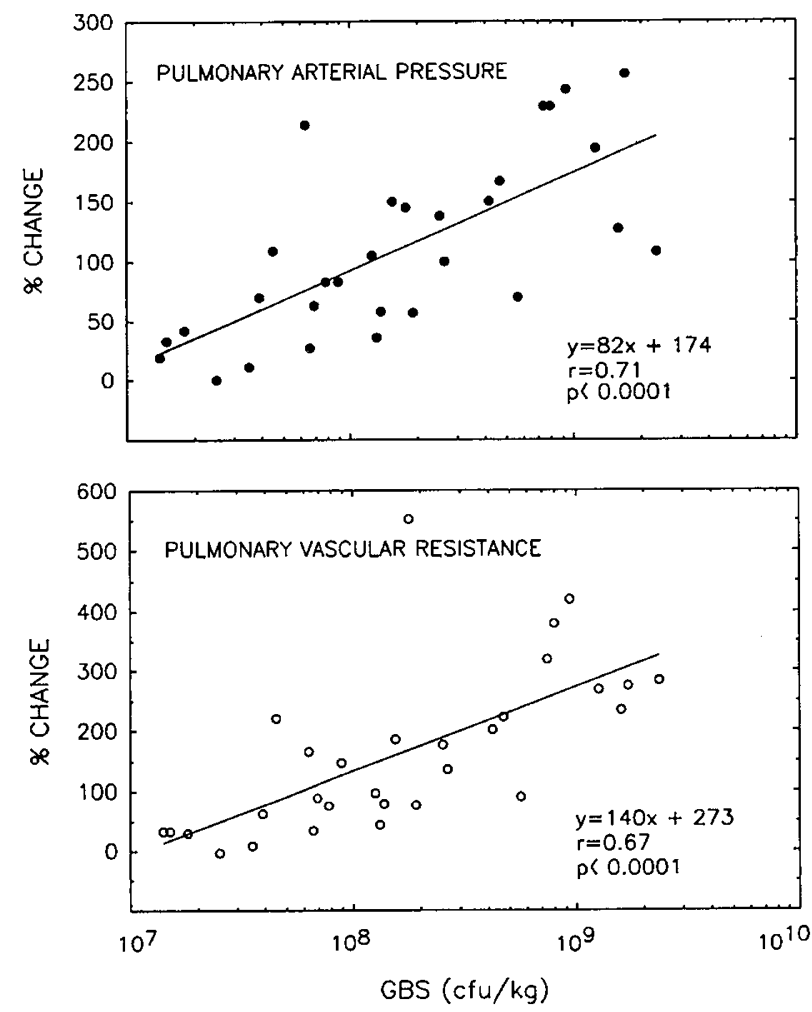

Fig. 2. Heat-killed GBS caused a dose-dependent increase in PAP [top, baseline $19.2(3.4 \mathrm{SD}) \mathrm{mm} \mathrm{Hg}$ ] and calculated PVR [bottom, baseline $\left.0.08(0.03 \mathrm{SD}) \mathrm{mm} \mathrm{Hg} \cdot \mathrm{mL}^{-1} \cdot \mathrm{min} \cdot \mathrm{kg}\right]$.
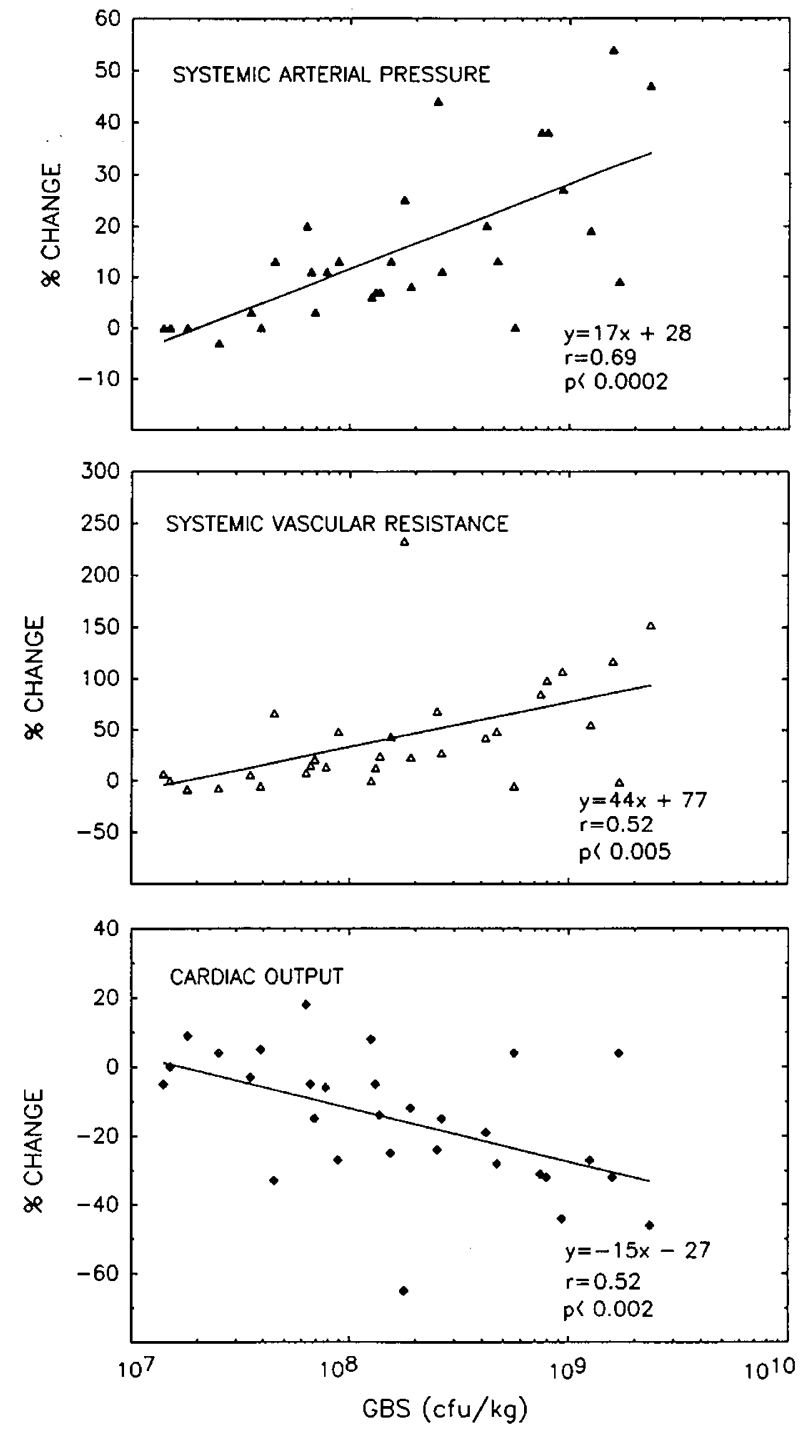

Fig. 3. Heat-killed GBS caused a dose-dependent increase in SAP [top, baseline $74.0(7.2 \mathrm{SD}) \mathrm{mm} \mathrm{Hg}$ ] and calculated SVR [middle, baseline $\left.0.30(0.09 \mathrm{SD}) \mathrm{mm} \mathrm{Hg} \cdot \mathrm{mL}^{-1} \cdot \mathrm{min} \cdot \mathrm{kg}\right]$ and a dose-dependent decrease in cardiac output (bottom, baseline $266.0 \mathrm{~mL} \cdot \mathrm{min}^{-1} \cdot \mathrm{kg}^{-1}$ ).

arterial $\mathrm{pH}$ or blood gas tensions, although oxygenation tended to decrease at the highest dose that each lamb received; arterial $\mathrm{O}_{2}$ pressure decreased from $11.2(1.7 \mathrm{SD})$ to $9.9(1.6 \mathrm{SD}) \mathrm{kPa}(p$ $=0.07$ ).

No attenuation or potentiation of the GBS-induced hemodynamic effects was observed when multiple doses were given throughout the day.

$L T D_{4}$ and LT Receptor Antagonism. Intravenous injection of $\mathrm{LTD}_{4}(1.0 \mu \mathrm{g} / \mathrm{kg})$ caused a significant increase in PAP and SAP and a decrease in cardiac output. These effects were completely blocked by both LY171883 and WY 48,252 (Fig. 4).

$G B S$ and LT Receptor Antagonism. Heat-killed GBS. LY171883 caused no changes in the baseline value of hemodynamic variables. It did, however, completely block the heat-killed GBS-induced increase in PAP ( $p<0.0001$, Fig. 5). The control injection of GBS, $1.0 \times 10^{9} \mathrm{cfu}$, increased PAP $100 \%$ from 18 to $36 \mathrm{~mm} \mathrm{Hg}$. After pretreatment with LY 171883, PAP increased $5 \%$ from 18 to $19 \mathrm{~mm} \mathrm{Hg}$. In addition, LY 171883 significantly attenuated the GBS-induced systemic hypertension and decrease in cardiac output $(p<0.05)$.

Intravenous injection of WY 48,252 caused a transient increase in PAP, which returned to baseline values before the injection of heat-killed GBS. This was believed to be secondary to the ethanol vehicle, inasmuch as ethanol alone also caused a 


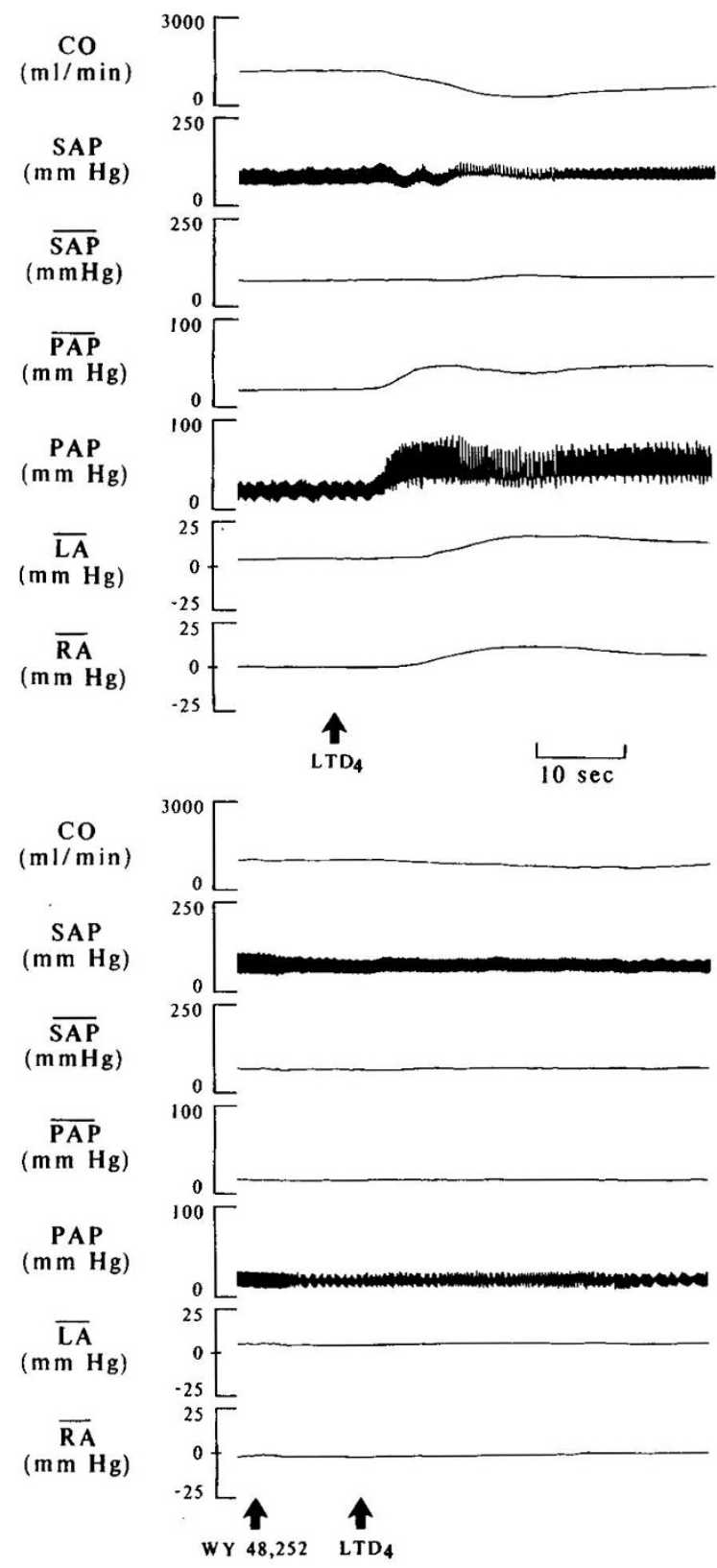

Fig. 4. Representative tracing of the hemodynamic effects of $\mathrm{LTD}_{4}$ $(1 \mu \mathrm{g} / \mathrm{kg})$ in a newborn lamb before (top) and after (bottom) giving it the $\mathrm{LTD}_{4}$ receptor antagonist WY 48,252. The drug blocked the $\mathrm{LTD}_{4-}$ induced decrease in cardiac output $(C O)$, increases in PAP and SAP; and increases in right $(R A)$ and left $(L A)$ atrial pressures.

transient increase in PAP. Therefore, it was given i.v. to only three lambs; the other five lambs received WY 48,252 enterally. The drug did not alter the baseline values when it was given enterally. WY 48,252 also attenuated the heat-killed GBS-induced increase in PAP. After pretreatment with WY 48,252, the maximum PAP response was attenuated $27 \%(p<0.05)$. The GBS-induced decrease in cardiac output was also significantly attenuated $(p<0.05)$. No apparent difference was observed between the effects when WY 48,252 was given parenterally or enterally.

Live GBS. Injection of live GBS $\left(1 \times 10^{9}\right)$ caused hemodynamic changes similar to those caused by heat-killed GBS; mean PAP increased $110 \%$ from 24.0 (2.0 SD) to $50.3(0.6 \mathrm{SD}) \mathrm{mm}$ $\mathrm{Hg}(p<0.05)$. Live GBS increased mean SAP from $73.3(2.9$ $\mathrm{SD})$ to $90.0(13.2 \mathrm{SD}) \mathrm{mm} \mathrm{Hg}$.

LY171883 blocked the live GBS-induced pulmonary hypertension. GBS increased mean PAP only $11 \%$ from 21.3 (4.2 SD)
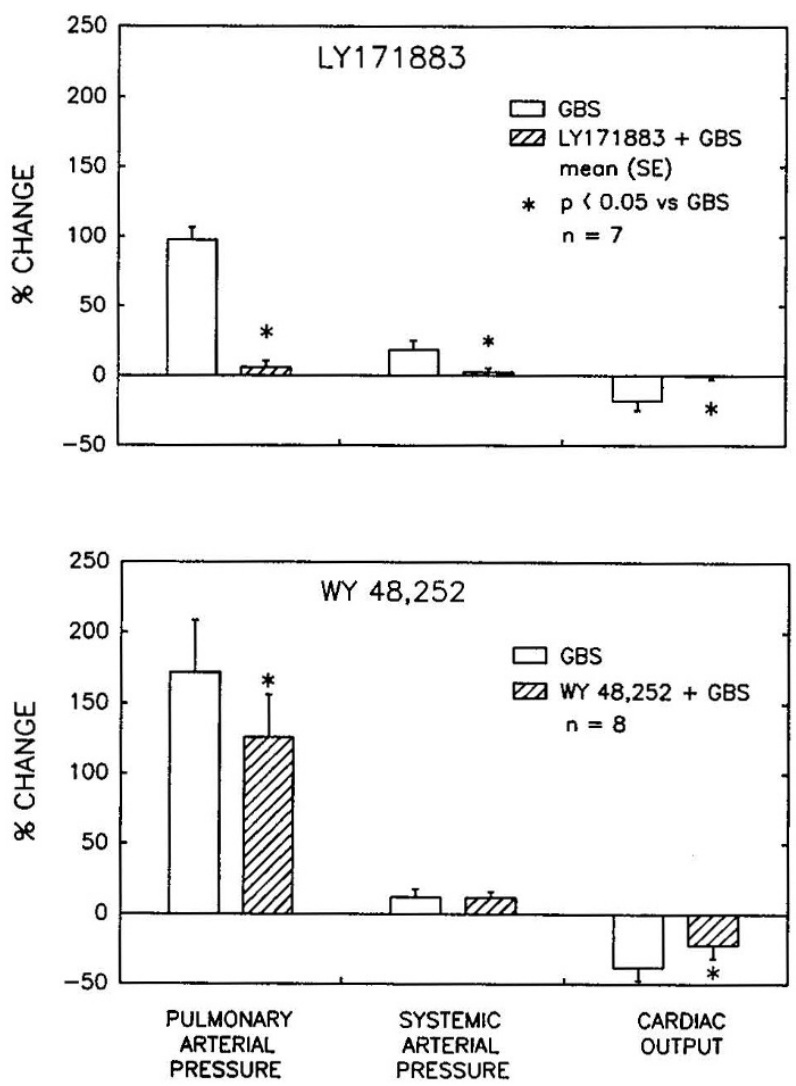

Fig. 5. The $\mathrm{LTD}_{4}$ receptor antagonist LY171883 (top) and WY 48,252 (bottom) blocked and attenuated GBS-induced pulmonary hypertension.

to 23.7 (4.5 SD) mm Hg; SAP was unchanged. These results are identical to those caused by heat-killed GBS (Fig. 5).

Left Atrial Injection of $G B S$. In three lambs, the two inferior vena cava injections each lamb received always produced similar hemodynamic effects. The two left atrial injections were also similar to each other. Left atrial injections caused systemic hemodynamic effects similar to inferior vena cava injections; SAP increased to 95.8 (16.6 SD) $\mathrm{mm} \mathrm{Hg}$ versus 98.3 (19.1 SD) $\mathrm{mm} \mathrm{Hg}$. Cardiac output decreased to 173 (19 SD) $\mathrm{mL} \cdot \mathrm{min}^{-1}$. $\mathrm{kg}^{-1}$ versus $206(19 \mathrm{SD}) \mathrm{mL} \cdot \mathrm{min}^{-1} \cdot \mathrm{kg}^{-1}$. PAP increased to a slightly lesser degree when GBS was injected into the left atrium: 43.6 (5.5 SD) $\mathrm{mm} \mathrm{Hg}$ versus 47.7 (2.1 SD) $\mathrm{mm} \mathrm{Hg}(p=0.10)$.

\section{DISCUSSION}

The results of this study demonstrate that injection of heatkilled GBS causes a dose-dependent increase in mean PAP, PVR, mean SAP, and SVR and a decrease in cardiac output in conscious newborn lambs. At a specific dose $\left(1 \times 10^{9} \mathrm{cfu}\right)$, heatkilled GBS causes reproducible pulmonary hypertension with minimal systemic effects. The structurally unrelated, putative $\mathrm{LTD}_{4}$ receptor antagonists, LY171883 and WY 48,252, can block or significantly attenuate this pulmonary hypertensive effect. In this model, these results are not unique to GBS that has been heat-killed inasmuch as livé GBS causes similar responses.

Previous studies have demonstrated in newborn lambs and adult sheep that the effects of an infusion of GBS on the pulmonary vasculature are similar to those of Escherichia coli endotoxin (3-10). Both cause a biphasic response. The initial early response includes pulmonary hypertension, hypoxia, neutropenia, and altered lung mechanics. This early phase begins immediately after the infusion and lasts approximately 1-2 h. This initial phase is followed by a second late phase that is characterized by continued, but less dramatic, pulmonary hyper- 
tension associated with an increase in protein-rich lung lymph flow that is indicative of pulmonary endothelial injury. This study predominantly investigated the early pulmonary hypertensive phase of GBS-induced lung injury. Because tachyphylaxis or potentiation, which has been reported when small doses are repeated $(6,8)$, has been observed, we verified that equal doses of GBS given during the same day would cause similar effects.

The first or early phase of GBS-induced and endotoxin-induced pulmonary hypertension is generally believed to be mediated by $\mathrm{TXA}_{2}$. Both cyclooxygenase synthesis inhibition and thromboxane synthesis inhibition decrease the GBS and endotoxin-induced increase in $\mathrm{TXB}_{2}$ (the measurable metabolite of $\mathrm{TXA}_{2}$ ) concentration and the increase in PAP (10-13). Because of the strong interaction between the cyclooxygenase and lipoxygenase pathways of arachidonic acid metabolism (15-18), we were interested in whether TXA $\mathrm{T}_{2}$ is the sole mediator or whether an interaction between $\mathrm{TXA}_{2}$ and the sulfidopeptide LT exists. Previous studies have reported that $\mathrm{TXA}_{2}$ can cause an increase in $\mathrm{LTC}_{4}$ and $\mathrm{LTD}_{4}$ production (17). A recent study suggests that $\mathrm{TXA}_{2}$-induced pulmonary hypertension is partially mediated through sulfidopeptide LT (18).

The contribution of sulfidopeptide LT to GBS-inducted pulmonary vasoconstriction in anesthetized piglets has been previously reported by Goldberg et al. (4). They demonstrated that the putative LT receptor antagonist FPL57231 blocks the early phase of GBS-induced pulmonary hypertension. Additional evidence that LT are involved in the control of the pulmonary circulation includes: FPL57231 blocking hypoxia-induced pulmonary hypertension in newborn (19) and adult sheep (20), oleic acid-induced pulmonary hypertension in newborn lambs (21), and $\mathrm{TXA}_{2}$ mimetic-induced pulmonary hypertension in newborn lambs (18), and FPL57231 dramatically increasing pulmonary blood flood flow in fetal sheep (22). The importance of LT has been supported using lipoxygenase synthesis inhibition to attenuate hypoxia-induced pulmonary hypertension in newborn lambs (23) and to increase pulmonary blood flow in fetal sheep (15). However, the reported nonspecific vasodilating properties of FPL57231 have always been a confounding factor (24).

The possible contribution of sulfidopeptide LT to the hemodynamic effects of $E$. coli endotoxin has previously been reported in adult sheep $(25,26)$, adult cats (27), and pigs (28), with conflicting results. In adult sheep, the sulfidopeptide LT receptor antagonist FPL57231 blocked the endotoxin-induced increase in PAP and pulmonary vascular pressure (25). Similar results were found in adult cats using slightly higher doses of FPL57231 (27). Although these results could be interpreted as caused by nonspecific pulmonary vasodilation caused by FPL57231, LY171883 also attenuated endotoxin-induced pulmonary hypertension in adult sheep (26) and to a lesser extent in anesthetized pigs (28). These data, along with our data, suggest that species, age, and methodologic differences, such as anesthesia, play important roles.

By using two unrelated putative $\mathrm{LTD}_{4}$ receptor antagonists (16), we addressed this methodologic concern (Fig. 1). LTD 4 receptor antagonists were selected because previous studies have shown that $\mathrm{LTD}_{4}$, not $\mathrm{LTC}_{4}$, is responsible for $\mathrm{LT}$-induced pulmonary hypertension in newborn lambs (29). LY171883 completely blocked GBS-induced pulmonary hypertension; WY 48,252 attenuated this response. At least two possible explanations account for the relative difference between these two drugs. First, LY171883 may have other properties besides $\mathrm{LTD}_{4}$ receptor antagonism. In high doses, LY171883 has been reported to be a phosphodiesterase inhibitor. In addition, at very high doses, higher than those used in this study, LY171883 is a relatively weak TX receptor antagonist $(16,30)$. Given the known importance of $\mathrm{TXA}_{2}$ in the early phase of GBS-induced pulmonary hypertension, this may have been an important factor. Second, although administered in nearly equimolar amounts, the bioavailability of these two drugs may differ.

WY 48,252 has previously been shown to block $\mathrm{LTD}_{4}$ and antigen-induced bronchoconstriction in adult sheep (31). The ability of WY 48,252 to block the hemodynamic effects of exogenous $\mathrm{LTD}_{4}$ has not previously been studied. At high concentrations; WY 48,252 has some inhibiting effect of 5-lipoxygenase and cyclooxygenase activity. It lacks any 12-lipoxygenase, 15-lipoxygenase, or phosphodiesterase activity (32). Although phosphodiesterase inhibition appears to be the major difference in mechanism of action between LY171883 and WY 48,252, this is unlikely to be the cause for the differences seen between these two drugs. LY171883, previously shown to block exogenous $\mathrm{LTD}_{4}$ in adult pigs (17), does not attenuate endotoxininduced bronchoconstriction (28), and our preliminary data demonstrate that aminophylline does not attenuate GBS-induced pulmonary hypertension (33).

The sulfidopeptide LT are produced by a variety of cells within the lung, including mast cells, alveolar macrophages, type II pneumocytes, and pulmonary vascular tissue (34-36). LT from these sources can be rapidly synthesized within the lung (36). They cause both arterial and venous constriction (37). Although LT concentrations have never been measured immediately $(1-2$ min) after lung insult, primarily because of methodologic difficulties (38), previous work in newborn lambs has shown the rapid onset of effect of $\mathrm{LTD}_{4}$ on the pulmonary and systemic circulations (29).

Because the major focus of this study was to attenuate the pulmonary hypertension induced by GBS, we chose a dose of GBS that caused predominantly pulmonary vascular changes with minimal systemic vascular effects. This strategy was used because the predominant morbidity and mortality from GBSinduced pulmonary hypertension seen clinically is severe pulmonary vasoconstriction with resultant severe hypoxemia. Other newborn infants, however, do sustain significant systemic vascular alterations when infected with GBS. Some investigators have suggested that the pulmonary vasculature of the newborn is more sensitive to vasoactive substances than the systemic circulation (39). If true, this could be due to more active conversion of $\mathrm{LTC}_{4}$ to $\mathrm{LTD}_{4}$ in the newborn. Other studies have suggested that the perinatal metabolism differs from the mature metabolism of arachidonic acid (40). Alternatively, in our study, GBS could have had predominantly pulmonary vascular effects because, when injected i.v., the pulmonary capillary bed received the highest concentration during the first pass. To test this possibility, we injected GBS into the left atrium of several lambs and found the systemic and pulmonary effects to be similar.

The documentation that heat-killed GBS causes similar hemodynamic changes with common mediators to live GBS is important. Multiple doses of heat-killed GBS can be administered without the concern for potential effects of live bacteria continuing to multiply within the host. Live bacteria must be grown immediately before use. Some variability in colony count may occur. Heat-killed bacteria may be stored for long periods of time, allowing serial studies to use the identical bacteria concentration. In addition, administration of antibiotics is not required, and the biohazard potential to laboratory staff is greatly reduced.

In conclusion, small bolus injections of heat-killed GBS may be a useful model to study the early pulmonary hypertensive phase of GBS-induced acute lung injury. In our conscious newborn lamb model, the pulmonary hypertension is mediated, in part, through sulfidopeptide LT. Modulation of LT may, therefore, be clinically important in the treatment of newborn infants with GBS-induced pulmonary hypertension.

Acknowledgments. The authors thank Dr. Joseph Chang of Wyeth-Ayerst Research, Princeton, NJ, for generously donating WY 48,252; Eli Lilly Research Laboratory, Indianapolis, IN, for supplying LY171883; Dr. William Meadow for supplying the GBS cultures; and Colleen Garcia for typing the manuscript. 


\section{REFERENCES}

1. Ingram DL, Pendergrass EL, Bromberger PI, Thullen JD, Yoder CD, Collier AM 1980 Group B streptococcal disease. Am J Dis Child 134:754-758

2. Pass MA, Gray BM, Khase S, Dillon HC 1979 Prospective studies of group B streptococcal infections in infants. J Pediatr 95:437-443

3. Brigham KL, Meyrick B 1986 Endotoxin and lung injury. Am Rev Respir Dis 133:913-927

4. Goldberg RN, Suguihara C, Streitfeld MM, Bancalari A, Clark MR, Bancalari E 1986 Effects of leukotriene antagonist on the early hemodynamic manifestations of group B streptococcal sepsis in piglets. Pediatr Res 20:10041008

5. Hellerqvist CG, Rojas J, Green RS, Sell S, Sundell H, Stahlman MT 1982 Studies on group B $\beta$-hemolytic streptococcus. I. Isolation and partial characterization of an extracellular toxin. Pediatr Res 15:892-898

6. Hemming VG, O'Brien WF, Fischer GW, Golden SM, Noble SF 1984 Studies of short-term pulmonary and peripheral vascular responses induced in oophorectomized sheep by the infusion of a group B streptococcal extract. Pediatr Res 18:266-269

7. O'Brien WF, Golden SM, Bibro MC, Charkobardi PK, Davis SE, Hemming VG 1985 Short-term responses in neonatal lambs after infusion of group B streptococcal extract. Obstet Gynecol 65:802-806

8. Philips JB, Lyrene RK, Godoy G, Graybar G, Barefield E, Sams JEP, Gray BM 1988 Hemodynamic responses of chronically instrumented piglets to bolus injections of group B streptococci. Pediatr Res 23:81-95

9. Rojas J, Green RS, Hellerqvist CG, Olegard R, Brigham KL, Stahlman MT 1981 Studies on group B $\beta$-hemolytic streptococcus. II. Effects on pulmonary hemodynamics and vascular permeability in unanesthetized sheep. Pediatr Res 15:899-904

10. Runkle B, Goldberg RN, Streitfeld MM, Clark MR, Buron E, Setzer ES Bancalari E 1984 Cardiovascular changes in group B streptococcal sepsis in the piglet: response to indomethacin and relationship to prostacyclin and thromboxane $A_{2}$. Pediatr Res 18:874-878

11. Rojas J, Larson LE, Ogletree ML, Brigham KL, Stahlman MT 1983 Effects of cyclooxygenase inhibition on the response to group B streptococcal toxin in sheep. Pediatr Res 17:107-110

12. Truog WE, Gibson RL, Juul SE, Henderson WR, Redding GJ 1988 Neonatal group B streptococcal sepsis: effects of late treatment with dazmegrel. Pediatr Res 23:352-356

13. Truog WE, Sorensen GK, Standaert TA, Redding GJ 1986 Effects of the thromboxane synthetase inhibitor, dazmegrel (UK 48,485), on pulmonary gas exchange and hemodynamics in neonatal sepsis. Pediatr Res 20:481-486

14. Zar JH 1974 Biostatistical Analysis. Prentice-Hall, Englewood Cliffs, NJ, pp $121-173$

15. Lebidosis J, Soifer SJ, Clyman RI, Heymann MA 1987 Piriprost: a putative leukotriene synthesis inhibitor increases pulmonary blood flow in fetal lambs. Pediatr Res 22:350-354

16. Musser JH, Kreft AF, Lewis AJ 1991 New developments concerning leukotriene antagonists: a review. Agents Actions 18:332-341

17. Olson NC, Fleisher LN 1989 Indomethacin and Ly171883 modify porcine cardiopulmonary responses in leukotrienes. Prostaglandins Leukotrienes Essent Fatty Acids 35:175-182

18. Soifer SJ, Schreiber MD, Heymann MA 1989 Leukotriene antagonists attenuate thromboxane-inducible pulmonary hypertension. Pediatr Res 26:83-87

19. Schreiber MD, Heymann MA, Soifer SJ 1985 Leukotriene inhibition prevents and reverses hypoxic pulmonary vasoconstriction in newborn lambs. Pediatr Res 19:437-441

20. Ahmed T, Oliver Jr W 1983 Does slow-reacting substance of anaphylaxis mediate hypoxic pulmonary vasoconstriction? Am Rev Respir Dis 127:566 571

21. Schreiber MD, Soifer SJ 1991 Hemodynamic effects of oleic acid in newborn lambs: role of arachidonic acid metabolism. J Dev Physiol 16:167-172

22. Soifer SJ, Loitz RD, Roman C, Heymann MA 1985 Leukotriene end organ antagonists increase pulmonary blood flow in fetal lambs. Am $\mathbf{J}$ Physiol 249:H570-H576

23. Soifer SJ, Schreiber MD, Frantz EG, Heymann MA 1986 Inhibition of leukotriene synthesis attenuates hypoxia-induced pulmonary vasoconstriction in newborn lambs. Pediatr Res 20:441A(abstr)

24. Gause GE, Baker R, Cassin S 1988 Specificity of FLP57231 for leukotriene D4 receptor in the fetal pulmonary circulation. Am J Physiol 254:H120 H 125

25. Ahmed T, Wasserman MA, Muccitelli R, Tucker S, Gazeroglu H, Marchette B 1986 Endotoxin-induced changes in pulmonary hemodynamics and respiratory mechanics. Role of lipoxygenase and cyclooxygenase products. Am Rev Respir Dis 134:1149-1157

26. Krausz MM, Dahan JB, Gross D 1988 Effect of the leukotriene receptor antagonist LY-171883 on endotoxemia in awake sheep. Circ Shock 26:431441

27. Pacitti N, Bryson SE, McKechnie K, Rodger IW, Parratt JR 1987 Leukotriene antagonist FPL57231 prevents the acute pulmonary effects of Escherichia coli endotoxin in cats. Circ Shock 21:155-168

28. Olson NC, Krus-Elliott KT, Johnson L 1990 Effect of LY171883 on endotoxininduced lung injury in pigs. J Appl Physiol 69:1315-1322

29. Schreiber MD, Heymann MA, Soifer SJ 1987 The differential effects of leukotriene $\mathrm{C}_{4}$ and $\mathrm{D}_{4}$ on the pulmonary and systemic circulations in newborn lambs. Pediatr Res 21:176-182

30. Fleisch JH, Rinkema LE, Haisch KD, Swanson BD, Goodson T, Ho PP Marshall WS 1985 LY171883, 1-[2-hydroxy-3-propyl-4-[4-(1H-tetrazol-5yl)butoxy]phenyl]ethanone, an orally active leukotriene $\mathrm{D}_{4}$ antagonist. Pharmacol Exp Ther 233:148-157

31. Abraham WM, Stevenson JS, Garrido R 1988 The effect of orally active leukotriene (LT) $\mathrm{D}_{4}$ antagonist WY-48,252 on LTD4 and antigen-induced bronchoconstrictions in allergic sheep. Prostaglandins 35:733-745

32. Chang J, Borgeat P, Schleimer RP, Musser JH, Marshall LA, Hand JM 1988 WY48,252 (1,1,1-trifluoro-N-13-(2-equinolinymethoxy)phenylmethanesulfonamide), an orally active leukotriene antagonist: effects on arachidonic acid metabolism in various inflammatory cells. Eur J Pharmacol 148:131-141

33. Schreiber MD, Torgerson LJ, Covert RF 1991 Effect of aminophylline on group B streptococcal and leukotriene induced pulmonary hypertension. Pediatr Res 29:188A(abstr)

34. Coceani F, Oiley IM 1988 Eicosanoids in the fetal and transitional pulmonary circulation. Chest 99:1125-1175

35. Cott GR, Westcott JY, Voelkel NF 1990 Prostaglandin and leukotriene production by alveolar type $\mathrm{H}$ cells in vitro. Am J Physiol 258:L179-187

36. Garcia JGN, Noonan TC, Jubiz W, Malik A 1987 Leukotrienes and the pulmonary microcirculation. Am Rev Respir Dis 136:161-169

37. Schellenberg RR, Foster M 1984 Differential activity of leukotrienes upon human pulmonary vein and artery. Prostaglandins $27: 475-481$

38. Westcott JY, Chang S, Balazy M, Stene DO, Pradelles P, MaClouf J, Voelkel NF, Murphy RC 1986 Analysis of 6-keto-PGFl $\alpha$, 5-HETE, and LTC in $_{4}$ rat lung: comparison of GC/MS, RIA, and EIA. Prostaglandins 32:857873

39. Rudolph AM 1979 Fetal and neonatal pulmonary circulation. Ann Rev Physiol 41:383-395

40. Soifer SJ, Morin FC, Heymann MA 1983 Developmental changes in the effect of prostaglandin $D_{2}$ on the pulmonary and systemic circulations in the newborn lamb. J Dev Physiol 5:237-250 